\title{
O PAPEL DO ADVOGADO NA GOVERNANÇA CORPORATIVA ATRAVÉS DO COMPLIANCE E DA GESTÃO DE RISCOS $^{1}$
}

THE PROBLEM OF THE JUDGE'S IMPARTIALITY IN THE BRAZILIAN CRIMINAL SYSTEM:

COMPARATIVE ANALYSIS BETWEEN BRAZIL AND ITALY

Priscilla de ANDRADE ${ }^{2}$

Maria Rafaela Junqueira Bruno RODRIGUES ${ }^{3}$

ISSUE DOI: $10.21207 / 2675-0104.2019 .953$

\section{RESUMO}

Fato notório em dias atuais é a presença de riscos nas empresas e a necessidade de mudança de postura para que haja seu melhor enfrentamento; com vistas a apresentar uma possibilidade para que essa realidade ocorra, a presente pesquisa visou estabelecer o papel do advogado na governança corporativa através da criação de programas de compliance e da gestão de riscos pelas empresas brasileiras. A adoção de programas de compliance e o importante papel do advogado para que haja sua implantação

\footnotetext{
${ }^{1} \mathrm{O}$ presente artigo sintetiza a monografia de conclusão da pesquisa, realizada para o Programa Interno de Bolsas de Iniciação Científica (PIBIC 2018-2019) da Faculdade de Direito de Franca (FDF), Franca/SP.

${ }^{2}$ Discente da Faculdade de Direito de Franca (FDF), Franca/SP. Bolsista do Programa Interno de Bolsas de Iniciação Científica (PIBIC 2018-2019).

${ }^{3}$ Graduação em Direito pela Faculdade de Direito de Franca (1991), Especialização em Metodologia do Ensino Superior (2001), Mestrado em Direito pela Universidade de Franca (2000), Especialização em Psicanálise Contemporânea (2006), Doutorado em Direito pela Universidade do Vale do Rio dos Sinos (2006), Pós Doutorado em Direito e Saúde na Università Degli Studi Di Messina - Itália (2014/2015), Aperfeiçoamento em Bioética Aplicada às Pesquisas em Seres Humanos (2013), Aperfeiçoamento em Educação para Jovens e Adultos pelo CEETEPS (2014) e Especialização em Gestão da Organização da Saúde Pública (UNIRIO/2014). Professora Universitária na Faculdade de Direito de Franca (2017) ministrando a Disciplina Direito Empresarial I.
} 
tem respaldo na legislação vigorante, que tentou regulamentar a situação fática, devendo não somente o tema, mas a legislação serem cada vez mais conhecidos e estudados, com vistas às melhorias de manutenção econômica das empresas, que reflete na sociedade de forma positiva. A metodologia utilizada na pesquisa consistiu no levantamento teórico interdisciplinar bibliográfico sobre à temática, consubstanciado em referenciais teóricos, artigos científicos dos cursos de Administração e Direito, para se estabelecer os conceitos necessários para compor o objetivo e o objeto da pesquisa e demais materiais encontrados via Web. Essa pesquisa trata do papel do advogado na governança corporativa, uma análise sobre os programas de compliance e modelos de governança corporativa com ênfase nos aspectos jurídicos. No entanto, em que pese o resultado ter sido alcançado, pois, o advogado terá através de seu desempenho profissional com relação à implantação do compliance nas empresas um papel extremamente importante para o contexto empresarial, social e econômico, não houve pretensão de se esgotar a temática, mas simplesmente apresentar um viés de possibilidade ao enfrentamento dos problemas que hoje se evidenciam nas empresas, pela falta de programas dessa natureza.

Palavras-chave: Compliance. Governança Corporativa. Empresas Brasileiras. Direito Empresarial.

\begin{abstract}
Well-established in the present day is the presence of risks and the need for change of posture for your best coping; with a view to presenting a chance for this to occur, the present research aims to establish the role of the lawyer in corporate governance through the creation of programs of compliance and risk management for Brazilian companies. The adoption of compliance programs and the important role of advocate for your deployment has support in invigorating legislation, which tried to regulate the theme, and not only the theme but the legislation being increasingly well known and studied, with views improvements to maintenance of companies, which reflects in society in a positive way. The methodology used in the research in theoretical interdisciplinary bibliographical survey on the theme embodied in theoretical references, scientific articles of administration and law, to establish the concepts needed to compose the aim and object of research and other found materials via the Web. This research deals with the role of the lawyer in corporate governance, an analysis of compliance programs and corporate governance models with legal approach. However, despite the result have been achieved, because the lawyer will have through your professional performance with respect to the implementation of compliance on companies an extremely important role for the business, social and economic context, claim runs out the theme, but simply introduce a bias of possibility to the confrontation of the problems evident in companies today, the lack of such programs.
\end{abstract}

Keywords: Compliance. Corporate governance. Brazilian companies. Business law.

\title{
$1 \quad$ INTRODUÇÃO
}

Diante da realidade cotidiana, a presença de vários riscos para as empresas e a necessidade de mudança de atitude, leva o administrador a repensar sua forma de atuar, uma vez que terá que buscar formas eficazes que o leve a enfrentar situações de crise. O papel do advogado na governança corporativa através do compliance e da gestão de riscos nas empresas se apresenta como uma possibilidade dada pela legislação vigorante às empresas que pretendem enfrentá-los e superá-los; sendo sua demonstração, portanto, o objetivo do presente trabalho.

$\mathrm{O}$ termo compliance tem origem no verbo em inglês to comply que na sua essência significa agir conforme uma regra, uma instrução interna, ou seja, estar em compliance é estar em conformidade com leis e 
regulamentos externos e internos. É a atividade de assegurar que a empresa esteja cumprindo a risca todas as imposições dos órgãos de regulamentação, dentro de todos os padrões exigidos de seu segmento isso vale para as esferas trabalhista, fiscal, contábil, financeira, ambiental, jurídica, previdenciária, ética, etc.

Tanto a governança corporativa que trata dos sistemas e métodos em que as empresas são dirigidas e administradas quanto os programas de Compliance são fundamentais nos dias atuais para que as empresas conquistem um aumento de competitividade através de boas práticas de organização, observâncias aos procedimentos legais e comprometimento ético ética que ainda ajudem na conquista de segurança jurídica na realização dos seus negócios.

Com essa visão estratégica da atuação do advogado nas empresas espera-se que as relações jurídicas se alinhem com uma postura preventiva através de uma gestão efetiva de riscos se utilizando de um programa de compliance dentro da realidade e com uma metodologia eficaz. Isso configura o advogado como parceiro estratégico da tomada de decisões das empresas, tendo um papel importante enquanto precursor da Quarta Revolução Industrial ora vivenciada.

Dessa maneira governança corporativa e compliance passam a ser investimentos em uma nova e melhor forma de se administrar empresas e conquistar competitividade em seus negócios, cuidando para que haja a prevenção quanto à possibilidade de futuros problemas que certamente não escapariam ilesos à empresa que atuar no mercado sem esse tipo de auxílio profissional.

O tema da pesquisa foi delimitado para um estudo em que se buscou um resultado prático proposto através do papel do advogado na governança corporativa através do compliance e da gestão de riscos nas empresas.

A questão de pesquisa se limita a responder a seguinte pergunta: É importante para empresa o papel do advogado na governança corporativa através do compliance e da gestão de riscos?

A presente pesquisa, dessa forma, justificou-se por ser uma proposta que apresenta ao Direito Empresarial uma alternativa de enfrentamento da crise, pois, ao se utilizar a governança corporativa a partir da adoção do compliance se possibilita uma gestão de caráter preventivo, baseada em uma visão que avalia riscos e consequências antecedendo à tomada de decisão e amortecendo os impactos que as empresas estão sujeitas no seu dia a dia. 
A metodologia utilizada nessa pesquisa consistiu no levantamento dos referenciais teóricos sobre o tema em livros e artigos científicos dos cursos de Administração e Direito e demais documentos e instrumentos de pesquisa para se estabelecer os conceitos necessários para compor o objetivo da pesquisa.

No entanto, resta mencionar que a presente pesquisa teve por finalidade ampliar os espaços de discussão de tão relevante tema nos dias atuais, mas, jamais, com a intenção de através dela, esgotar-se o tema.

\section{O PAPEL DO ADVOGADO NA GOVERNANÇA CORPORATIVA}

A função do advogado deveria ser de compreender as expectativas e as necessidades dos seus clientes para poder atender as suas respectivas demandas de maneira inteligente e não somente com uma visão do Direito contencioso como ensinado nas universidades em sua grande maioria, mas do Direito preventivo que pensa no problema antes mesmo até que ele apareça.

Isso verdadeiramente consiste numa oportunidade para os profissionais da área jurídica com relação às empresas, pois, serão um diferencial frente à concorrência que espera o problema vir à tona para tomar medidas que constituem somente em responder a uma demanda judicial e tentar minimizar os impactos financeiros e de imagem.

A advocacia tradicional trata de custos do processo já a advocacia de vanguarda trata de investimentos de melhorias e otimização de recursos. De acordo com MAMEDE E MAMEDE (2015. p.7):

(...) seria a superação do paradigma de servir o advogado
essencialmente para a demanda, o litígio, e inovar para assimilar a
idéia de que o advogado é mais útil quando aponta o caminho
correto, o mais seguro, ou até, o melhor caminho, entre as
alternativas juridicamente possíveis.

Atualmente é senso comum que os escritórios busquem advogados com espírito empreendedor, que tenham a capacidade de gerar novos negócios. A bagagem técnica que é muito valiosa deve ser acrescida da habilidade comercial.

Portanto, há uma necessidade de mudança na mentalidade dos profissionais da área jurídica, tendo em vista às mudanças, fruto da 
inserção de tecnologias inovadoras, fruto da Quarta Revolução Industrial . De agora em diante, ter visão de negócios e espírito empreendedor é fundamental para garantir empregabilidade e ascensão na carreira, o que na verdade consiste essencialmente na advocacia de vanguarda. Cada vez mais, a sociedade brasileira demanda advogados que trabalhem prevenindo litígios; consultores que definam o caminho melhor e mais seguro para os negócios, respeitando a lei, alcancem o sucesso desejado pelas partes. (MAMEDE E MAMEDE, 2015, p. 57)

A Lei 8.906/94 - Estatuto da Advocacia e da Ordem dos Advogados do Brasil, em seu artigo $1^{\circ}$, inciso I, define que são atividades privativas da advocacia tanto a postulação a qualquer órgão do Poder Judiciário e aos juizados especiais, quanto no inciso II se acham previstas as atividades de consultoria, assessoria e direção jurídica como privativas da advocacia.

O próprio legislador previu a utilidade do advogado como aquele profissional que desempenha uma função preventiva quanto a preservar e não permitir lesões a direitos e não somente como aquele que peticiona ao Judiciário. O inciso I se relaciona a advocacia tradicional e o inciso II a advocacia de vanguarda também conhecida como preventiva.

A advocacia como qualquer área de conhecimento tem que acompanhar a própria evolução das empresas o que exige atualmente uma postura proativa perante o mercado para competir de maneira diferenciada, mas com segurança jurídica para obter um desenvolvimento sustentável para a sociedade.

Mas a sustentabilidade jurídica não é uma atitude de mera sujeição. Comporta, sim, uma expressão proativa, o que se faz a partir da utilização dos instrumentos modernos disponibilizados pela tecnologia jurídica. Assim, há caminhos diversos, estratégias diferentes, para se garantir a sustentabilidade jurídica de um patrimônio, de uma empresa. Há formas mais onerosas e outras menos onerosas. (MAMEDE E MAMEDE, 2015, p.11)

Quando uma empresa se utiliza de tecnologia jurídica, que pode se apresentar como sinônimo de advocacia preventiva, o que ela busca é evitar o litígio. Através de um sistema de inteligência jurídica é possível mapear os pontos vulneráveis da empresa do ponto de vista técnico-legal e agir antes que ocorra alguma falha que gere um processo que poderá custar muito caro para a empresa e sacrificar muitas vezes o seu planejamento estratégico e principalmente a sua imagem perante a sociedade. 
Infelizmente, ao contrário do que se passa em outros países, não há no Brasil uma cultura de valorização da tecnologia jurídica, nem da busca da sustentabilidade jurídica. O advogado é encarado como um demandista, ao qual se recorre para mover ações ou se defender delas, ou seja, alguém a quem se recorre quando já há um problema e jamais para impedir que o problema ocorra. E isso tem um custo altíssimo. (MAMEDE E MAMEDE, 2015, p. 12)

A valorização do Direito Processual e da ação são enganosas: o litígio é a falha do Direito, não sendo sua melhor tradução. A maioria das relações jurídicas alcança suas finalidades. Se há litígio é porque o Direito falhou. (MAMEDE E MAMEDE, 2015, p. 55)

É senso comum perceber que além da adoção das mudanças tecnológicas, os negócios precisarão ser geridos de acordo com demandas atuais e por pessoas com mentes abertas, com afeição ao novo, com alta resiliência e sem medo de experimentar, errar e aprender. Só assim as empresas (e os escritórios de advocacia) estarão preparadas para as mudanças que o futuro reserva (GRACIOTTI, 2016, p.23).

A advocacia preventiva lança mão de uma ferramenta bastante relevante nos dias atuais, que é o compliance que se trata de uma das maneiras de obter vantagem competitiva que é justamente a adoção de uma governança corporativa que significa estar em consonância com as leis e com as políticas e normas internas e externas e buscar a prevenção, a detecção e a resposta para problemas jurídicos nas organizações.

A principal vantagem competitiva a ser alcançada pela empresa será o fortalecimento de sua estrutura organizacional e a valorização de sua marca consequentemente o valor de mercado.

Observa-se que a empresa deve buscar uma sustentabilidade jurídica para os seus negócios e para as suas relações com os seus stakeholders, e assim, para que ela possa prosperar no mercado de maneira segura e constante.

O consultor jurídico deve participar dos debates sobre o presente e o futuro da empresa, mas em um primeiro momento é importante analisar o seu passado para poder identificar as melhorias e mudanças que podem ser implementadas no departamento jurídico para evitar litígios e assumir uma postura proativa perante aos acontecimentos.

As empresas privadas em grande parte carecem de informações jurídicas desde o momento de sua concepção, inclusive, por parte do(s) administrador(es) denota responsabilidade profissional, necessária à 
própria função exercida, como se pode constatar dos termos previstos no art. 1.011 e 1016, ambos do Código Civil.

Todas as estratégias planejadas pelas empresas devem considerar os respectivos impactos jurídicos. O estudo de implicações e impactos jurídicos nas organizações acabam contemplando: o exame da licitude da estratégia proposta, definição de requisitos legais, formalidades legais, análise de riscos jurídicos e custos legais e extralegais para apontar o melhor caminho a ser seguido em termo de lucratividade e de segurança jurídica.

Esse processo não é algo simples de ser feito porque envolve além do conhecimento técnico-jurídico mudanças nos aspectos da cultura da empresa. Sair do discurso e ir para a prática requer mais do que investimento financeiro, exige disposição de enfrentar os erros e brigar pelos acertos.

Uma mudança de paradigma da advocacia tradicional para a advocacia de vanguarda pode até levar tempo, mas com certeza não há outro caminho, afinal cada dia fica mais difícil não seguir a lei.

O Instituto Brasileiro de Governança Corporativa apresenta o conceito de governança corporativa como "o sistema pelo qual as empresas e demais organizações são dirigidas, monitoradas e incentivadas, envolvendo o relacionamento entre os sócios, conselho de administração, diretoria, órgãos de fiscalização e controle e demais partes interessadas.

As boas práticas de governança corporativa convertem princípios básicos em recomendações objetivas, alinhando interesses com a finalidade de preservar e otimizar o valor econômico de longo prazo da organização, facilitando seu acesso a recursos e contribuindo para a qualidade da gestão da organização, sua longevidade e o bem comum." (disponível em http://www.ibgc.org.br, acesso em 07 de abril de 2018)

Em síntese a governança corporativa trata do relacionamento entre os stakeholders internos e externos à organização em que se ressaltam: as práticas que visam a transparência dos atos e políticas, a igualdade no tratamento dos membros da sociedade e, principalmente, a responsabilidade corporativa dos resultados e obrigações perante a justiça. As práticas de governança ajudam a empresa a comprovar o seu comprometimento com a ética.

A governança corporativa, da forma como é aplicada no Brasil, surgiu como reflexo do modelo americano. Segundo Vidigal in Leal e Camuri $($ p.61, 2008) a palavra "governance" origina-se do verbo latino gubernare, que em português significa governar. Dentro deste contexto, 
governança seria o meio pelo qual os acionistas administram uma empresa ou organização.

É através de uma governança corporativa sólida que as empresas conseguem um crescimento consistente e seguro. Leal e Camuri (p.61, 2008) relacionam em seus estudos algumas definições do termo governança corporativa, em que alguns casos deve ser compreendida como protetora das partes envolvidas através de um conjunto de leis e regulamentos que visam assegurar os direitos dos acionistas e disponibilizar informações que permitam o acompanhamento das decisões empresarias importantes. E outros casos trata dos meios utilizados pelas corporações para estabelecer processos que ajustam os interesses em conflito entre os acionistas das empresas e seus dirigentes de alto nível. $\mathrm{Ou}$ ainda governança como estrutura de poder que regem os mecanismos através dos quais as companhias são dirigidas e controladas.

Sob a ótica global o termo governança corporativa passou por um processo de mudança, em que o entendimento atual diz respeito a padrões de comportamento que conduzem a um crescimento sustentável da empresa tendo por base princípios definidos pela ética e compliance na gestão da empresa o que envolve além dos acionistas todos os stakeholders.

No atual contexto econômico e social, em que a transparência é uma exigência cada vez maior do mercado e da sociedade, é fundamental que o advogado que atua ou que pretenda trabalhar na área de Direito Empresarial tenha familiaridade com os conceitos de governança corporativa em todos os aspectos jurídicos que envolvem as organizações, assim como com seus aspectos legais e demais assuntos que com ela se relacionam.

A governança engloba ações voltadas para o reforço da reputação da organização garantindo: os benefícios internos de se trabalhar em regularidade ética e a vantagem competitiva de ser reconhecida como empresa íntegra e confiável nos limites além da sua estrutura, sempre observando o cumprimento dos aspectos legais, além das normas de dever profissionais, deontológicas, próprias de cada estabelecimento.

O operador do direito tem a missão de orientar a empresa para que se consiga implementar mecanismos de governança corporativa para que se alcance um desenvolvimento sustentável dos negócios e um ambiente competitivo mais saudável entre os competidores.

Além desses aspectos, a empresa que adotar em sua rotina a governança corporativa demonstra que detém em seu sistema 
organizacional profissionais de alta envergadura comprometidos e responsáveis, principalmente com a sociedade onde se acham inseridos.

\section{PROGRAMAS DE COMPLIANCE}

O período de transformação moral que o Brasil tem passado nos últimos anos leva a acreditar que num futuro muito próximo as empresas brasileiras terão que se adequar à nova realidade brasileira que exige um meio de integridade e transparência formal em sua estrutura através da governança corporativa e do compliance.

Essa postura na gestão que permite a adoção de tais qualidades possui características que são asseguradas por um Programa de Compliance ou como chamado na lei de Programa de Integridade que se trata de uma ferramenta pela qual uma organização garante que a sua atuação está seguindo as normas do mercado.

O programa de compliance contempla as especificidades de cada empresa, pensando no seu setor e local de atuação. Assim, garante que a organização explore todo o seu potencial dentro do que determina a lei. Impõe uma fiscalização dos trabalhos realizados pelos funcionários dentro da empresa.

Constituem também atenuantes previstos em lei que são considerados nas punições a serem aplicadas inclusive nos acordos de leniência em muitos casos. A empresa que comprova que tomou todas as medidas para evitar o ato de corrupção que está sendo acusada terá uma redução significativa ou até isenção de penalidade.

$\mathrm{O}$ artigo $7^{\circ}$, inciso VIII, da Lei Anticorrupção enuncia que a existência de mecanismos e procedimentos internos de integridade, auditoria e incentivo à denúncia de irregularidades e a aplicação efetiva de códigos de ética e de conduta no âmbito da pessoa jurídica serão levadas em consideração no momento da aplicação das sanções. Em outras palavras, a lei nº 12.846/2013 está concedendo benefício de atenuação de pena às empresas que inserirem efetivamente procedimentos de combate à corrupção, como códigos de ética e de conduta, bem como canal de ouvidoria e de denúncia, a fim de prevenir a prática de ilicitudes e implantar uma mudança cultural no modo de agir das pessoas jurídicas que contratam com o Poder Público. (CAMPOS, 2015, p. 174) 


\begin{abstract}
Diante disso, verifica-se que há uma expectativa de que as empresas que pactuam com a Administração Pública se conscientizem aos poucos do efeito pedagógico e repressivo das sanções e, visando obter a concessão da atenuante prevista no artigo $7^{\circ}$, elaborem o programa de compliance, definido como "ato de cumprir, de estar em conformidade e executar regulamentos internos e externos, impostos às atividades da instituição, buscando mitigar o risco atrelado à reputação e ao regulatório/legal. (MANZI, 2008, p.15).
\end{abstract}

A importância dos programas de compliance, ainda tem o respaldo legal, no sentido de que atenua para a organização que o tem em seu sistema de gestão, portanto, conditio sine qua non para êxito da empresa.

O compliance trabalha apoiado não apenas na regularidade com as leis, mas, sobretudo com a transparência de dados e informações do negócio, apresentando tudo aquilo que é útil para comprovar que a empresa honra com as suas obrigações e cumprimento das normas.

Sem dúvida alguma os escândalos de corrupção recentes na história do país contribuíram para que o Compliance ocupasse um lugar de destaque dentro da realidade nacional e fosse incorporado no vocabulário dos brasileiros.

Até 2013, somente as pessoas físicas poderiam ser punidas em atos de envolvimento com corrupção e não as empresas. Atualmente, no Brasil, qualquer empresa que "pratica" ato ilícito que é capaz de ser enquadrado como ato de corrupção pode ser responsabilizada de maneira objetiva, essa mudança significativa causou impacto direto nas organizações.

A palavra Compliance vem da língua inglesa e é um substantivo que se origina da palavra "to comply with" que significa agir de acordo com, ou seja, de acordo com uma lei, uma norma ou uma política interna da empresa. Conforme, a evolução da utilização desse termo também foi alterando a sua abrangência e a sua principal aplicação atual refere-se a agir de acordo com a Lei Anticorrupção.

Em resumo um programa de Compliance existe para que a pessoa jurídica crie mecanismos que impeça a prática de atos ilícitos como: corrupção ou fraude.

Isso reforça o conceito de que a pessoa jurídica que cometeu ato ilícito contra a administração pública terá sua responsabilidade analisada de maneira objetiva enquanto os administradores, considerados pessoas naturais, terão sua responsabilidade analisada de maneira subjetiva. 
A responsabilização da pessoa jurídica não exclui a responsabilidade do administrador enquanto pessoa física natural, assim, devendo ambos responderem nos limites impostos pelas respectivas legislações transgredidas.

DAL POZZO et al $(2015$, p. 39$)$ ressalta que "a pessoa jurídica ainda não responderá objetivamente se seu representante (ou preposto) agiu para, deliberadamente, prejudicar a empresa que representa: neste caso há interrupção do nexo de causalidade."

A responsabilidade civil dos envolvidos é de extrema importância e reconhecida como fator de proteção aos terceiros de boa-fé e, portanto, a importância de seus institutos é reconhecida, permeando o ordenamento jurídico, como exposto.

Em que pese haver a responsabilidade penal e a responsabilidade civil, haverá ainda de ser responsabilizar às pessoas jurídicas no que diz respeito ao cometimento de um ilícito administrativo, desta feita ressalta CAMPOS (2015, p.167) que "na esfera administrativa, as sanções aplicáveis às pessoas jurídicas responsáveis pelos atos lesivos são multa e publicação extraordinária da decisão condenatória".

Outro aspecto importante é a publicação da condenação da empresa por ato de corrupção ou outro contra a Administração Pública em meios de comunicação de grande circulação, e, até no seu website o que pode causar um grande abalo em sua reputação.

É também possível obrigar a empresa a reparar integralmente o dano causado, podendo haver a desconsideração da personalidade jurídica e o bloqueio de bens pessoais dos administradores da empresa, a suspensão e interdição parcial das atividades e até mesmo a dissolução compulsória da empresa em casos mais graves.

A Lei Anticorrupção $n^{\circ} 12.846 / 2013$ é necessária para o desenvolvimento sustentável e pleno da sociedade brasileira, tendo através da instituição do sistema de compliance para as pessoas jurídicas, estabelecendo meios para o enfrentamento da corrupção. Os resultados tornar-se-ão visíveis a médio e longo prazo, dependendo do que haja êxito da correta aplicação da Lei e da físcalização social.

No contexto das organizações é possível verificar que a corrupção é um fator impeditivo ao desenvolvimento social por tratar-se da falência dos valores ético-morais e da insustentabilidade das relações institucionais e comercias.

Prevê a Lei Anticorrupção $n^{\circ} 12.846 / 2013$ a responsabilidade objetiva das empresas, em que não há necessidade de comprovação de 
culpa da pessoa jurídica considerada corrupta, mas tão simplesmente tenha sido praticado o ato de corrupção e o nexo de causalidade. Para tanto, institui-se que para as pessoas jurídicas com práticas de corrupção, mecanismos internos, tais como o compliance (ou conforme está na lei o programa de integridade) bem como a criação de cadastro de empresas punidas, como forma de sanção.

O Decreto $n^{\circ} 8420$, de 18 de março de 2015, descreve parâmetros de avaliação da efetividade dos programas de compliance e depende ainda das características da própria pessoa jurídica, tais como a quantidade de colaboradores, funcionários e empregados, da complexidade da hierarquia interna, da utilização de agentes intermediários como consultores ou representantes comerciais, do setor e do país em que se atua.

Por outro lado se a empresa conseguir comprovar que possui um programa efetivo de Compliance e for comprovado que o ato de corrupção foi algo isolado de um funcionário ou gestor será mais fácil de comprovar o não envolvimento dos outros.

Existem dois fatores que justificam o crescimento dos programas de Compliance no Brasil que são: uma tendência mundial de moralização das práticas comerciais com consequente crescimento de investimento em Compliance e o clima político de incertezas e de restrições regulatórias. Construir uma nova conduta de conformidade, colocando a empresa no caminho da ética e da integridade assegura uma vantagem competitiva a ser analisada pelos investidores.

Cada programa de Compliance é único já que os riscos de cada empresa também são únicos. Diferentemente da ética, que é assumida com espontaneidade, o compliance está relacionado a responsabilidade legal. Ser ético é agir voluntariamente com princípios morais para a sociedade. Já compliance é cumprir com regras e regulamentos; é trabalhar ou agir dentro da lei. (ANTONIK, 2016, p.47)

Após o trabalho de diagnóstico da situação atual da empresa frente aos aspectos normativos e legais que regulam o seu setor, a confecção do código de ética, das condutas, das políticas internas e das análises do mapa de riscos em que a empresa possui. Parte-se efetivamente para os elementos de um programa de compliance.

O primeiro elemento é o accountability, que visa definir os papéis e responsabilidades dentro do organograma da empresa. Basicamente visa definir quem faz o que dentro da organização, qual a sua responsabilidade, suas tarefas e responsabilidades dentro da hierarquia da empresa. 
Analisa-se os recursos materiais, o orçamento, as pessoas, por isso é tratado como elemento do alicerce do programa de compliance semelhante à construção de uma casa. Por isso, se nessa fase algo sai errado todo o programa fica comprometido, porque como cada empresa é única não adianta tentar replicar programa de uma para outra. Nessa fase tem também que se destinar uma verba para o programa e comprometimento do topo da empresa ao reafirmar como serão as regras na empresa a partir daquele momento.

\footnotetext{
A palavra accountability significa a prestação de contas por uma entidade administrativa aos seus reguladores. A expressão "prestar contas" poderia ser uma tradução resumida para o termo. Accountability refere-se àqueles que precisam explicar para uma instância superior o que, como, por que e por quanto fazem o que fazem. (ANTONIK, 2017, p.200)
}

O segundo elemento trata-se da execução de um mapa de todas as leis que se aplica a atividade da empresa, se trata das normas externas, questões regulatórias e autorregulatórias e dos projetos de lei no âmbito Municipal, Estadual e Federal que estão em discussão para evitar que a empresa seja pega de surpresa. Esse elemento demonstra que o compliance pode ser estratégico, pois, antecipa-se a concorrência. Como a lei é dinâmica nesse momento deve ser definido quem vai fazer o trabalho de acompanhamento e monitoramento constante de todo o arcabouço regulatório que envolve a empresa.

Chamado de políticas e procedimentos, o terceiro elemento, analisa as normas internas da organização, sendo o código de conduta, a lei interna principal da empresa, que reflete sobre os valores intrínsecos e as políticas de conflitos de interesses. Nesse momento criam-se procedimentos detalhados com o que deve ser feito quando algo ocorrer de acordo com as políticas. Um exemplo clássico é a contratação de um parente em que será necessário analisar quais serão os critérios e qual o procedimento que a empresa utiliza. Permite-se ou não a contratação desse parente, se permite quais são as condições, como será feito o processo.

Como quarto elemento, temos o treinamento e a comunicação, conscientizando todos os colaboradores da empresa sobre o que devem conhecer referente as suas atividades. Esse treinamento pode ocorrer de maneiras diversas: online, presencial, jogos, teatro ou gibi. Pode-se também utilizar do modelo de embaixadores trabalhadores que têm a sua respectiva função dentro da empresa e acumulam a atividade de serem multiplicadores do programa de compliance. 
O quinto elemento consiste em verificar a aplicabilidade prática no mundo real da empresa da atividade de monitoramento, pois, deve-se achar uma maneira eficaz de checar se tudo aquilo que se estabeleceu realmente acontece na realidade inclusive com a figura do terceiro agindo em nome da empresa.

Chamado de Issue management, o sexto elemento trata da maneira como a empresa responde à verificação dos problemas encontrados pelo compliance. Os testes são feitos juntamente com os controles e acabam encontrando alguma coisa que contraria a ordem estabelecida pela empresa, nesse momento é necessário oferecer uma resposta pela empresa.

O assunto deverá ser tratado como uma força de violação as políticas ao código de conduta da empresa. Por exemplo: dentro de um comitê jurídico pode-se verificar quais são as principais causas de pedir dentro daquela organização, ou porque a empresa tem tanto processo em determinada área como exemplo hora extra. A partir da identificação do problema analisa-se a causa-raiz, o objetivo é acabar com a causa. Buscar uma melhor performance para a empresa, tem que se preparar também para as mudanças que podem ocorrer no campo regulatório dessa causa-raiz.

O procedimento de certa maneira é simples tudo deve ser coordenado dentro da empresa, se encontrar algum desvio de corrupção tem que verificar as políticas, saber o porquê do monitoramento não ter identificado o problema. Verificar para quem deverá ser reportado o problema; é importante observar como obteve-se a informação, por exemplo: se for por canal de denúncia tem que oferecer a garantia de anonimato, observar se deve ir a polícia, tomar as atitudes necessárias para defender a empresa.

O sétimo elemento é conhecido como reporting e tem como objetivo compreender e analisar as razões que levaram a empresa a chegar naquela situação, de maneira a contribuir com o andamento do relatório adiante, para a alta direção da companhia ainda que eles não queiram saber.

A direção da empresa tem o direito e o dever de tomar conhecimento da real situação. Pelo ordenamento jurídico não há o direito a cegueira deliberada e a responsabilidade da empresa é objetiva.

É muito importante que a organização desenvolva canais de comunicação que permitam ao público interno e externo da empresa realizarem denúncias de suspeitas de irregularidades que estejam ocorrendo no âmbito da empresa conforme o que está descrito no artigo 42, inciso X do Decreto Lei no 8.420 de março de 2015. 
A capacitação e treinamento dos profissionais e colaboradores da empresa são fundamentais juntamente com seus respectivos stakeholders em relação ao conhecimento dos valores, das regras da empresa e das normas internas para que tudo ocorra conforme o alinhamento estratégico da organização.

Os pilares de um programa de compliance bem estruturado envolvem a análise de perfis de riscos e a estratégia de monitoramento constante. Identificam-se as normas internas da empresa que tratam de processos sujeitos a risco de corrupção, fraude e integridade.

\footnotetext{
"A previsão de compliance na Lei $\mathrm{n}^{\circ}$. 12.846/2013 constitui um avanço direcionado à ética e à transparência das relações negociais entre a Administração Pública e o setor privado. Ademais, trata-se de um sinal de que a empresa deve adotar um determinado padrão de conduta compatível com uma boa-fé objetiva." (CAMPOS, 2015, p. 174)
}

A prevenção faz parte de qualquer objetivo de compliance que trabalha numa visão macro, com a idéia de futuro identificando-se hoje para solidificar a estrutura da empresa e capacitar as pessoas a terem conhecimento para que não ocorram problemas futuros. Detecta para os colaboradores possuírem as ferramentas necessárias para identificar de maneira oportuna e rápida os riscos. A resposta rápida e eficaz soluciona 0 problema e evita que ele se repita, e assim, desestimulando para que ele não ocorra novamente.

Dessa maneira, os administradores devem colaborar com o compliance no sentido de documentarem as atividades da empresa para que possam ser utilizadas em momento oportuno. Um dos exemplos de documentação jurídica derivada dos programas de compliance que podem auxiliar no desenvolvimento de uma empresa é o Código de ética, as condutas e as políticas internas.

Depois se sugerem medidas preventivas e corretivas para sanar ou minimizar os riscos que ficarão documentados, a fim de melhorar o ambiente de trabalho, aumentar a produtividade, diminuir o passivo trabalhista, reduzir as multas aplicadas pelo Ministério do Trabalho e conter os litígios. Trata-se de um diferencial competitivo e de governança corporativa, que tem como conseqüência o crescimento sustentável da empresa.

Como se constata munidas as organizações das documentações pertinentes, o programa de compliance passa a atender de maneira 
mais eficaz as organizações, correspondendo aos anseios a que se propõe.

\section{MODELOS DE GOVERNANÇA CORPORATIVA COM ENFOQUE JURÍDICO}

A administração é uma arte, no sentido de profissão ou área de ação humana. Toda arte depende de habilidades. O desempenho dos administradores depende de suas competências gerenciais, que incluem diversas habilidades gerenciais. As habilidades, assim como as demais competências podem ser adquiridas ou aprimoradas por meio de experiência e estudo. (MAXIMIANO,2000, p.28)

Segundo Bertalanffy, a tecnologia e a sociedade tornaram-se tão complexas que as soluções tradicionais da administração não são mais suficientes. É necessário utilizar abordagens de natureza holística ou sistêmica, generalistas ou interdisciplinares. (IN MAXIMIANO, 2000, p.69)

Reconhecer que o mundo é dinâmico e que as mudanças ocorrem em uma velocidade cada vez maior faz com que a administração tenha um viés sistêmico, em que a empresa a ser administrada se insere dentro de um contexto de interdependência das outras empresas e que sem a visão do todo é impossível repensar o seu próprio espaço.

A complexidade das análises a serem feitas do ambiente para poder competir exige do administrador um olhar holístico com conhecimento interdisciplinar até para poder calcular os riscos enfrentados frente aos objetivos a serem alcançados e maximizar os seus resultados.

Pelo próprio sistema organizacional que envolve a estrutura de uma empresa, há aspectos éticos, sociais, jurídicos, dentre outros, no entanto, com relação ao tema governança corporativa e os programas de compliance, se destacam os éticos e os sociais, assim, ANTONIK (2016), faz a seguinte definição sobre a palavra ética:

A palavra ética deriva do grego "ethikos" e significa aquilo que faz parte dos bons costumes. É importante diferenciar os aspectos morais dos éticos. A moral tem como fundamento a obediência aos hábitos e aos costumes da sociedade, da família e da religião. A ética, por sua vez, tem como base outra definição conceitual e busca na razão a solidez para os seus conceitos. (ANTONIK, 2016, p. 23) 
Um programa de governança corporativa juntamente com compliance consiste no aprimoramento e desenvolvimento da cultura ética, de acordo com as leis e normas regulatórias aplicáveis em rotinas administrativas e negociais, bem como por meio de valores e políticas empresariais.

É necessário que o proprietário da empresa e os respectivos acionistas apoiem o programa de compliance dentro da empresa. Sem esse suporte, o programa não será efetivo, pois, carece de legitimidade. Antes de iniciar o trabalho deve se fazer uma matriz de risco, com um mapeamento mínimo dos riscos reais da empresa para somente depois organizar um código de conduta e ética da empresa.

A confecção de um programa de compliance feito sob medida é trabalhoso e demanda profissionalismo e tempo. Adquirir um programa pronto pode ser um grande equívoco e tornar a empresa ainda mais vulnerável, gerando um custo ainda mais alto, ao tentar adaptá-la a uma realidade que não é a dela. Não há como transmitir os valores apenas no papel, o código de ética tem que refletir a cultura da empresa, os seus atos e reflexos de conduta no seu cotidiano.

As empresas exercem um papel fundamental na sociedade e pensar estrategicamente de maneira responsável nas suas decisões não traz nenhum ônus pelo contrário faz com que a sua imagem torne-se valiosa no mercado.

A ética empresarial traduz a filosofia e os objetivos fundamentais de um negócio. Uma companhia tem como objetivo trazer o máximo de retorno sobre os investimentos dos acionistas. Caso abra mãos dos lucros, ela estará traindo a confiança da missão que lhe foi delegada. Do mesmo modo, o corpo gerencial dessa firma, respeitados os limites fixados por ela mesma, principalmente, o regramento estabelecido na lei, deve na sua tarefa de gestão, maximizar os retornos. (ANTONIK, 2016, p.46)

Todas as estratégias planejadas pelas empresas devem considerar os respectivos impactos jurídicos. O estudo de implicações e impactos jurídicos nas organizações acaba contemplando: o exame da licitude da estratégia proposta, definição de requisitos legais, formalidades legais, análise de riscos jurídicos e custos legais e extralegais para apontar o melhor caminho a ser seguido em termo de lucratividade e de segurança jurídica. (ANDRADE, 2017, p.32)

Dessa maneira o programa de governança corporativa com compliance abrange éticas internas de conduta, aspectos gerais da legislação vigorante e ainda, as normas de gestão administrativa que 
equilibram as relações envolvendo a organização internamente e externamente, de maneira a evitar-se qualquer tipo prática de corrupção por parte das pessoas jurídicas e de seus administradores.

Com essa visão estratégica da atuação do advogado nas empresas privadas espera-se que as relações jurídicas se alinhem com o Direito evitando o risco de litígios e as perdas diversas, garantidas por uma postura preventiva e positiva da atuação do advogado como parceiro estratégico na tomada de decisões nas empresas brasileiras privadas.

Ao se tratar de um ambiente de atuação cada vez mais globalizado das empresas não há como não pensar de maneira estratégica principalmente nos aspectos jurídicos em que cada erro resulta em uma sanção ou perda, em que muitas vezes pode literalmente falir a empresa e inviabilizar os seus negócios para sempre.

A relevância da pesquisa proposta também é notória em decorrência da necessidade constante das empresas de reduzir os seus custos numa tentativa de maximizar os seus lucros e talvez os aspectos jurídicos sejam uma das últimas fronteiras a serem rompidas, principalmente nas pequenas e médias empresas privadas que não possuem ninguém observando os fatores de risco, utilizando-se dos serviços jurídicos somente como parte processual e não na obtenção de vantagem competitiva.

A administração tem que deixar de ser uma atividade intuitiva e passar a racionalizar suas atividades não pensando somente em tarefas, mas principalmente nas consequências dos seus atos. Ao realizar o exercício de formular hipóteses sobre o futuro o administrador passa inclusive a ter que pensar nas demandas da sociedade e como poderá satisfazê-las.

Nesse momento o ordenamento jurídico oferece a segurança para os investimentos e ás vezes sinaliza para caminhos menos tortuosos para se obter o que precisa, pode vir desde de uma lei de incentivo à exportação de produtos para se ganhar mercado até de uma lei de isenção de impostos para importação de máquinas, dentro outros.

E a pessoa mais indicada para auxiliar o administrador nesse momento é justamente um advogado que tem uma visão da advocacia preventiva porque vai poder analisar o ambiente em que a empresa está inserida e apontar as ameaças e oportunidades técnico-jurídicas para a empresa construir seu desenvolvimento de maneira sólida e com segurança legal.

Nesse contexto as empresas se diferenciam se há no seu organograma profissionais capazes e aptos, com respectivo conhecimento 
do ordenamento jurídico e seu conteúdo, além de condutas e posturas éticas que os habilitem como líderes.

Pergunta-se: já que o ordenamento jurídico vale para todos por que somente alguns conseguem usufruir dos benefícios que a lei pode oferecer na rotina do seu dia a dia? Sem dúvida alguma isso se refere à aplicabilidade da lei ao caso concreto. E num mundo em que cada vez se torna mais competitivo e globalizado, com consumidores com acesso as informações mais diversas em tempo real, conhecer a realidade em que se está inserido deixou de ser um diferencial passou a ser uma comodities.

Os resultados precisam ser sustentados. A qualidade planejada tem que coincidir com a qualidade de conformidade, ou seja, o produto ou serviço tem que ter qualidade, se não precisará ser refeito, descartado, consertado ou indenizado. Dentre os aspectos que a falta de qualidade gera estão: a perda de clientes, uma projeção de imagem pública negativa, retrabalho no conserto de produtos e serviços que ainda estão em garantia além das eventuais despesas processuais quando esses problemas saem do controle e acaba se formando uma relação processual para resolver o litígio na jurisdição em decorrência da ausência de um acordo entre as partes.

É interessante observar que como o Direito regula a vida em sociedade todas as atividades da empresa nele esbarram, no sentido de apresentar o que pode ou não pode ser feito num primeiro momento e depois pode até ser utilizado como diferenciação já que no cenário brasileiro infelizmente obedecer a legislação acaba se tornando até selo estampado em produto como aquele que diz:"essa empresa não utiliza trabalho infantil, empresa amiga da criança, empresa amiga do meio ambiente", dentre outros.

Para atuar em uma empresa (organização) proativa o advogado não pode ser somente processualista precisa ter um pensamento de vanguarda em tentar lidar com eventos futuros conhecidos, ou que se sabe que ocorrerão e afetarão a organização de alguma forma. Em muitos casos, é possível prever, com maior ou menor precisão, os fatos futuros e seus efeitos, estudando o ordenamento jurídico, a doutrina e a jurisprudência.

A organização formaria um banco de dados aplicado ao seu processo decisório em que as decisões programadas que se aplicam a problemas que são familiares ou repetitivos seriam consultados dentro do sistema de informações próprio para evitar erros e atitudes contrárias a cultura organizacional. Seria um conjunto de decisões que resolvem os problemas recorrentes, que acontecem todos os dias e exigem as mesmas decisões e soluções a cada ocorrência. 
A tarefa do departamento jurídico atuando como staff numa organização seria diante de uma decisão estratégica procurar o melhor resultado possível, ao custo mais baixo, o que consiste numa decisão maximizada. A maximização do processo decisório exige a identificação e a análise criteriosa de todas as alternativas, que devem ser comparadas entre si desde o momento da identificação do problema, ao diagnóstico, geração de alternativas e adecisão final.

Alguns fatores podem afetar o comportamento do tomador de decisão mesmo diante da orientação do departamento jurídico como: tempo, inteligência, ética, informação, percepção, competências, propensão ao risco, recursos. Mesmo assim com a orientação técnicojurídica estratégica é possível minimizar os impactos e os riscos assumidos.

\section{CONSIDERAÇÕES FINAIS}

Ensino jurídico segundo FUX (2000, p.174) é o veículo através do qual se transmite ao estudante de Direito a visão do fenômeno jurídico na sua dupla configuração a saber: o sistema de leis e as formas de composição dos conflitos jurídicos decorrentes da irrealização espontânea do Direito.

Conclui-se que o principal estímulo para uma empresa adotar um programa de governança corporativa e compliance em sua estrutura é justamente o que a lei anticorrupção busca que são:

a) Criação de uma política eficaz de combate a corrupção;

b) Confecção de um manual de conduta e código de ética de acordo com a cultura da empresa;

c) Criação de um canal de denuncia para apurar os eventuais desvios de conduta e garantir o anonimato a quem faz a denuncia;

d) Acompanhamento e monitoramento da legislação que envolve o setor em que atua e a sua atividade;

e) Realização periódica de auditorias;

f) Treinamento e capacitação para os colaboradores e todos envolvidos com a empresa, inclusive os terceiros que não estão dentro de sua estrutura organizacional;

Esses aspectos contribuem para o desenvolvimento das empresas e de maneira geral para que haja uma sociedade mais justa e ética. As empresas que não têm condições de possuir uma estrutura de governança 
corporativa e compliance e gerir o seu próprio programa tem a alternativa de contratar escritórios terceirizados especializados que podem suprir essa lacuna, mas mesmo assim, não estarão cumprindo para com os ditames legais e nem mesmo para um compromisso ético, respaldado em uma cultura que deseja ser consolidada no mundo empresarial.

Em que pese tais considerações, o espaço de discussão necessita ser cada vez mais amplo, para disseminar a cultura dos programas de governança corporativa e compliance nas empresas, assim como, a presente pesquisa deseja contribuir.

Sendo assim, é possível concluir que a governança corporativa e o compliance devem ser desenvolvidos de maneira conjunta para que se consiga obter resultados satisfatórios em termos de crescimento e sustentabilidade dos negócios e o advogado constitui peça fundamental nesse cenário, seja atuando de maneira preventiva ou controlando as demandas contenciosas para que não se repitam.

Observa-se que os modelos de governança corporativa adotados por empresas de outros países já vêm colhendo seus frutos e conseguindo um ganho de imagem e conseqüentemente espaço num mercado cada vez mais competitivo e exposto a vulnerabilidades.

A ética nos negócios não é mais questão de escolha, mas de sobrevivência, responsabilidade profissional e comprometimento social.

\section{REFERÊNCIAS}

AGUIAR, Roberto A. R. de. A crise da advocacia no Brasil: diagnóstico e perspectivas. 3.ed..São Paulo: Alfa- Omega. 1999.

ANDRADE, Adriana. ROSSETTI, José Paschoal. Governança corporativa: fundamentos, desenvolvimento e tendências. 2.ed..São Paulo: Atlas, 2006.

ANDRADE, Priscilla de. Atuação estratégica do advogado nas empresas privadas. Orientadora Prof ${ }^{\mathrm{a}}$. Dr ${ }^{\mathrm{a}}$. Iara Marthos Águila. Trabalho de Iniciação Científica Faculdade de Direito de Franca. Franca, SP: 2017.

ANDRADE, Priscilla de. A relação entre a Lei Anticorrupção n 12.846/2013 e a criação de programas de Compliance por empresas brasileiras. Orientadora Prof ${ }^{a}$. Dr ${ }^{\mathrm{a}}$. Maria Rafaela Rodrigues Bruno Junqueira. Trabalho de Iniciação Científica Faculdade de Direito de Franca. Franca, SP: 2018.

ANTONIK, Luís Roberto. Compliance, ética responsabilidade social e empresarial: uma visão prática. Rio de Janeiro: Alta Books, 2016. 
ASSI, Marcos. Governança, Riscos e Compliance-mudando a conduta nos negócios.São Paulo: Saint Paul, 2014.

BASTOS, Aurélio Wander. O Ensino Jurídico no Brasil. Rio de Janeiro: Lumem Juris, 1998.

BANDEIRA DE MELLO, Celso Antônio. Curso de direito administrativo. São Paulo: Ed. Malheiros, 2013, 30. ed.

BLOK, Marcella. Compliance e Governança Corporativa.Rio de Janeiro: Freitas Bastos Editora, 2.ed., 2018.

CAMPOS, Patrícia Toledo de. Comentários à Lei no 12.846/2013 - Lei anticorrupção. Revista Digital de Direito Administrativo- RDDA. Faculdade de Direito de Ribeirão Preto. Universidade de São Paulo, v. 2, n. 1, p. 160-185, 2015.

CARVALHO FILHO, José dos Santos. Manual de direito administrativo. São Paulo: Atlas, 2013.

CARLIM, Everson Luis Breda.Criando Valor nas Organizações - do compliance à proteção patrimonial- como tornar uma empresa um alvo atrativo.Curitiba: Juruá Editora, 2017.

CHIAVENATO, Idalberto. Introdução à teoria geral da administração.6.ed.. Rio de Janeiro: Elsiever, 2000.

CUNHA FILHO, Alexandre Jorge Carneiro da; ARAÚJO, Gláucio Roberto Brites de; LIVIANU, Roberto; PASCOLATI JÚNIOR, Ulisses Augusto (coords.). 48 visões sobre a corrupção. São Paulo: Quartier Latin, 2016.

CUNHA, Rogério Sanches; SOUZA, Renée. Lei anticorrupção empresarial. Salvador: Ed. JusPodivm, 2017.

DAL POZZO, Antônio Araldo Ferraz et al. Lei anticorrupção: apontamentos sobre a Lei n. 12.8462013. São Paulo: Editora Contracorrente, 2015, 2.ed.

DANTAS, Francisco Wildo Lacerda. Manual jurídico da empresa. Brasília, DF: Livraria e Editora Brasília, 1998.

DUTRA, Lincoln Zub (Org.). Compliance no ordenamento jurídico brasileiro.Curitiba: Juruá Editora, 2018.

FUX, Luiz. O novo ensino jurídico. Revista da EMERJ. Rio de Janeiro: EMERJ v.3, n. 9, 2000, p.174-179.

GRACIOTTI, José Paulo. Tendências do negócio jurídico. In REVISTA Visão Jurídica, p.23, ano 10 edição $124,2016$.

GRINOVER, Ada Pellegrini. O advogado e a formação jurídica.1978 p.103 a 114 Disponível em: https://www.revistas.usp.br/rfdusp/article/viewFile/66847/69457 - Acesso em 13.ago.2017. 
HAGE, Jorge. Lei Anticorrupção vai mudar a atitude do empresariado brasileiro. Carta Capital. Disponível em: <http://www.cartacapital.com.br/politica/lei-anticorrupcao-vai-mudar-atitude-ementalidade-do-empresariado-brasileiro201d-2906.html>. Acesso em 27.mar.2017.

LEAL, Maria José. CAMURI, Walter César. A governança corporativa e os modelos mundialmente praticados. Revista de Ciências Gerenciais, Vol XII, n.15, ano 2008. p. 59-74

MACHADO, Antônio Alberto. Ministério Público: democracia e ensino jurídico. Belo Horizonte: Del Rey, 2000.

MAMEDE,Gladston. e MAMEDE, Eduarda Cotta. Blindagem Patrimonial e Planejamento Jurídico.5.ed..São Paulo: Ed. Atlas, 2015.

MANZI, Vanessa Alessi. Compliance no Brasil. São Paulo: Saint Paul, 2008.

MAXIMIANO, Antônio Cesar Amaru. Introdução á Administração. 5.ed..São Paulo: Atlas, 2000.

MOREIRA, Igor de Souza Mêrcedo e MOREIRA, Ivan de Souza Mêrcedo. Empreendedorismo legal: condução estratégica do contencioso: desenvolver estratégias de atuação que extrapolem o domínio técnico-jurídico. Publicado em www.migalhas.com.br em 04.04.2016. Acesso em 13.08.2017.

NALINI, José Roberto. O Futuro das Profissões Jurídicas. São Paulo: Oliveira Mendes, 1998.

OLIVEIRA, José Sebastião de; CARVALHO, Thomaz Jefferson. Aspectos da crise jurídica no Brasil e a visão de Paulo Freire. Revista Jurídica Cesumar, Mestrado, v. 10, n. 2 p. 567-589, jul./dez. 2010

PORTER, Michael E. tradução de Elizabeth Maria de Pinho Braga. Revisão técnica Jorge A. Garcia Gomes. Estratégia Competitiva técnicas para análise de indústria e da concorrência. 7.ed.. Rio de Janeiro: Ed. Campus, 1986.

REIS, José Jeronimo Reis. A criação de novos serviços na logística jurídica perspectivas para um futuro próximo. Publicado em www.migalhas.com.brem 01.08.2015.

SALOMÃO, Heloísa Estellita. (Coord.). Direito Penal Empresarial. São Paulo: Dialética, 2001.

SERPA, Alexandre da Cunha Serpa. Compliance descomplicado. São Paulo:CCPE, 2016. 